\title{
O DIREITO À SAÚDE E A IDEIA DE PROTEÇÃo SOCIAL NA CONSTITUIÇÃO FEDERAL DE 1988: Notas Iniciais
}

\section{Edith Maria Barbosa Ramos}

Pós-doutora em Direito Sanitário pela Fundação Oswaldo Cruz - Fiocruz/Brasília/DF. Doutora em Políticas Públicas pela Universidade Federal do Maranhão. Mestre em Direito pela Universidade Federal de Minas Gerais. Graduada em Direito pela Universidade Federal do Maranhão. Professora do Departamento de Direito e do Mestrado em Direito e Instituições do Sistema de Justiça da Universidade Federal do Maranhão. Coordenadora do Núcleo de Estudos em Direito Sanitário (Nedisa/UFMA). Professora e pesquisadora da Universidade do Ceuma. Professora do Imec. Membro convidado da Rede Ibero-Americana de Direito Sanitário. Presidente da Comissão de Bioética e Biodireito do ConseIho Seccional da OAB/MA. edithramosadv@yahoo.com.br

\section{Isadora Moraes Diniz}

Mestre em Direito e Instituições do Sistema de Justiça (UFMA). Pós-graduanda em Direito Processual Civil (Damásio Educacional). Graduada em Direito (UFMA). Professora do Imec. Integrante do Núcleo de Estudos em Direito Sanitário (Nedisa/UFMA). edithramosadv@ yahoo.com.br

\section{Resumo:}

0 presente artigo objetiva realizar uma análise do direito à saúde a partir do processo da consolidação dos direitos sociais insculpidos na Constituição Federal de 1988. Para tanto realiza-se incursão histórica inicial sobre o processo de constituição da concepção de proteção social. Objetiva-se, ainda, analisar a proteção social enquanto fator basilar da cidadania, a seguridade social como núcleo do Estado de Bem-Estar e discutir o contexto de inserção da questão do direito à saúde na agenda pública. Este texto utiliza o método descritivo exploratório com pesquisa bibliográfica e documental, visando a um aprofundamento teórico para a efetivação do esclarecimento dos motivos da análise. 0 acesso à bibliografia foi realizado pelos modos manual e eletrônico. A apropriação dos conceitos de proteção social e direitos sociais permitiu uma reflexão das determinações dos conteúdos presentes na concepção de direito à saúde, para posteriormente subsidiar a análise da ideia de cidadania.

\section{Palavras-chave:}

Proteção social. Cidadania. Direito à saúde. Constituição Federal.

\section{Revista}




\title{
THE RIGHT TO HEALTH AND THE IDEA OF SOCIAL PROTECTION \\ IN THE FEDERAL CONSTITUTION OF 1988: initial notes
}

\begin{abstract}
:
This article aims to carry out an analysis of the right to health based on the consolidation of the social rights inscribed in the Federal Constitution of 1988. For this purpose, an initial historical incursion is made on the process of constitution of the concept of social protection. It also aims to analyze social protection as a basic factor of citizenship, social security as the core of the Welfare State and discuss the context of insertion of the issue of the right to health in the public agenda. The present work uses the exploratory descriptive method with bibliographical and documentary research, aiming at a theoretical deepening to the clarification of the reasons for the analysis. Access to the bibliography was done by manual and electronic modes. The appropriation of the concepts of social protection and social rights allowed a reflection of the determinations of the contents present in the conception of right to health, to later subsidize the analysis of the idea of citizenship.
\end{abstract}

\section{Keywords:}

Social protection. Citizenship. Right to health. Federal Constitution.

Recebido em: 19/4/2016

Aceito em: 4/10/2017

\section{Sumário:}

1 Introdução. 20 direito à saúde no contexto da proteção social. 30 direito à saúde no Brasil. 4 Considerações Finais. 5 Referências. 


\section{INTRODUÇÃO}

O presente artigo objetiva realizar uma análise do direito à saúde a partir do processo da consolidaçáo dos direitos sociais insculpidos na Constituição Federal de 1988. Para tanto realiza uma incursão histórica inicial sobre processo de construção da concepção de proteção social no mundo.

Objetivou-se fazer uma reflexão sobre a proteção social enquanto fator basilar da cidadania, a partir das reflexóes desenvolvidas por Marshall (1967). Destacou-se que no século 19, a pobreza era vista como desvio de caráter, uma propensão individual à vagabundagem e mendicância. Perspectiva que vinculou intrinsecamente a possibilidade de assistência à prestação de um trabalho correspondente. Empreendeu-se demonstrar que as causas efetivas da pobreza deixaram de ser consideradas, pois foram subestimados os efeitos sociais das transformações econômicas e políticas.

Buscou-se, ainda, compreender a pobreza como produto do desenvolvimento predatório do capitalismo e que as mobilizaçôes das classes trabalhadoras modificaram significativamente a arena política, a moldura jurídica e o conceito de cidadania no século 20. Colocou-se em evidência a necessidade de reinvenção do capitalismo, no período seguinte à Segunda Guerra Mundial e como foi forjado o modelo de Estado de Bem-Estar Social.

Destacou-se a ideia de mínimos sociais e a inserção dos direitos sociais como elemento integrante do status da cidadania. Abordou-se a seguridade social como núcleo do Estado de Bem-Estar e discutiu-se o contexto de inserção da questão do direito à saúde na agenda pública. Evidenciou-se os principais documentos internacionais para demonstrar que o direito à saúde está relacionado com as condiçôes de vida das pessoas e que a Constituição Brasileira de 1988 representa instrumento singular na proteção do direito à saúde no país. O direito à saúde, no Brasil, esta inserto no capítulo sobre a seguridade social, fundamentada nos princípios da universalidade e da igualdade. Por fim, destacou-se que o direito à saúde ultrapassa questôes biológicas e que inclui a questão social em seu cerne. Ressaltou-se a criação do Sistema Único de Saúde e analisou-se as interfaces do direito à saúde, em especial seus princípios e diretrizes norteadores. 
Por essa razão, o presente trabalho utiliza o método descritivo exploratório, com pesquisa bibliográfica e documental, visando a um aprofundamento teórico para a efetivação do esclarecimento dos motivos da análise. $\mathrm{O}$ acesso à bibliografia foi realizado pelos modos manual e eletrônico. Por meio da apropriação dos conceitos de proteção social e direitos sociais buscou-se uma reflexão das determinaçóes dos conteúdos presentes na concepçáo de direito à saúde, para posteriormente analisar a ideia de cidadania. Deve-se ressaltar que se procurou a superaçáo de posturas metodológicas rígidas, demarcando a análise em diversas variáveis contextuais (jurídicas, sociais, econômicas e políticas) a fim de que se evitasse consideraçóes maniqueístas e sem objetivação científica e se conseguisse empreender uma investigação socialmente situada.

\section{DIREITO À SAÚDE NO CONTEXTO DA PROTEÇÃO SOCIAL}

Não há como discutir direito à saúde sem antes fazer uma incursão, ainda que sucinta, na temática da proteção social como fator basilar da cidadania, que, segundo Marshall (1967), está dividida em três elementos: o civil, o político e o social, os quais, ao menos na sociedade inglesa (que é a analisada na obra do autor), foram se desenvolvendo e se incorporando ao conceito durante três séculos.

O elemento civil da cidadania formou-se no decorrer do século 18, sobretudo em razão do trabalho dos tribunais, que pouco a pouco foram adicionando ao status do homem livre uma série de direitos essenciais ao exercício da liberdade individual, quais sejam: a liberdade de ir e vir; a liberdade de imprensa, pensamento e fé; o direito à propriedade e o de concluir contratos válidos; o direito à justiça e o direito de trabalhar.

Já os direitos políticos começaram a ser formados no século 19, "quando os direitos civis ligados ao status de liberdade já haviam conquistado substância suficiente para justificar que se fale de um status geral de cidadania” (MARSHALL, 1967, p. 69). A formação destes direitos não se caracteriza pelo surgimento de novos direitos, mas sim pela distribuição de velhos direitos a vários setores da populaçáo marginalizados politicamente. Dessa forma, paulatinamente ampliaram-se 
aos indivíduos o direito à participação no exercício do poder político, como um membro de um organismo investido da autoridade política ou como um eleitor dos membros de tal organismo.

Os direitos sociais, por sua vez, passaram a compor o status da cidadania somente no século 20, no entanto as bases incipientes dos serviços públicos como prestação do Estado começaram a ser lançadas ainda no século 19 com a Lei dos Pobres de 1834, que previa a concessão de prestaçóes sociais pelo Estado não enquanto direitos, mas segundo o paradigma da caridade a fim de aliviar os efeitos indesejados da miséria extrema.

Nessa época, os indivíduos para se valerem da assistência social precisavam se despir de todos os direitos de cidadania, renunciando a sua liberdade, rompendo seus laços familiares e se submetendo a jornadas de trabalho excessivas.

A pobreza era vista quase como um crime, um desvio de caráter que fazia com que o indivíduo, não acometido por qualquer incapacidade, ficasse propenso à vagabundagem e à mendicância. Assim, era dos pobres, portanto, a culpa pela pobreza. Por isso, não poderia haver qualquer assistência sem a prestação de um trabalho correspondente (PEREIRA, 2008).

Dessa forma, durante a vigência da Lei dos Pobres, as verdadeiras causas da pobreza não foram consideradas, na medida em que eram subestimados os efeitos sociais da rápida transformação da economia agrária para a industrial, da transferência de forma abrupta da vida social do campo para a cidade, do desemprego decorrente dos avanços tecnológicos, das flutuaçôes dos salários, das precárias, perigosas, insalubres e extenuantes exigências de trabalho e da ausência de educação e lazer. Todos esses elementos expuseram "inevitavelmente a fragilidade da doutrina utilitarista que atribuía ao pobre e às antigas Poor Laws a culpa pelo pauperismo" (PEREIRA, 2008, p. 79). Giovanni (1998, p. 31) destaca, ainda, que:

Inicialmente na Inglaterra e depois nos outros países europeus, os processos de industrialização e urbanização trouxeram o agravamento dos problemas ligados à pobreza (até então relativamente controlados). As péssimas condiçóes de trabalho vigentes entre a massa proletária que se constituía, o infortúnio, os acidentes, as doenças profissionais e o desemprego tornavam-se cada vez mais evidentes. A conjugaçáo de todos estes fatores - aliada à crescente organizaçáo 
das classes trabalhadoras através de sindicatos, a constituição de partidos políticos de inspiraçáo socialista comunista ou laborista, no bojo da expansão dos direitos políticos - evidenciaria, no plano das visóes de mundo de então, que a pobreza não era uma decorrência dos méritos (ou deméritos) e performances pessoais, mas um fenômeno ligado a uma relação muito estreita com as condiçóes sociais de vida e, particularmente, de trabalho. Ou pelo menos, que se estava diante de outro tipo de pobreza: não aquela dos párias, dos loucos e doentes, mas a pobreza paradoxal daqueles que trabalhavam.

Com efeito, a Revolução Industrial elevou ao máximo a exploração do homem, que era submetido a uma longa jornada de trabalho em troca de um mísero salário, situação que agravou o quadro de pobreza e, por conseguinte, os problemas sociais que a ela se associavam.

Percebeu-se que a pobreza náo era fruto da vagabundagem, mas sim produto do próprio desenvolvimento predatório do capitalismo, que explorava ao máximo o trabalho em nome do capital, resultando na contraditória existência da opulência e da riqueza ao lado da miséria absoluta.

Nesse contexto, e como consequência da expansão dos direitos civis e políticos, aumentaram as mobilizaçóes sociais, especialmente dos trabalhadores que lutavam em prol da melhoria das condiçóes de vida e de trabalho, circunstância que, conforme Pereira (2008), resultou nas batalhas pelo alargamento do conceito de cidadania das esferas civil e política para a social, de modo que os trabalhadores passaram a requerer as prestaçóes sociais como direitos devidos pelo Estado.

Polanyi (1980, p. 163-164) observa que a história social e política do século 19 foi marcada por um duplo movimento, que pode ser personificado como

[...] a açáo de dois princípios organizadores da sociedade, cada um deles determinando seus objetivos institucionais específicos, com o apoio de forças sociais definidas e utilizando diferentes métodos próprios. Um foi o princípio do liberalismo econômico, que objetivava estabelecer um mercado auto-regulável, dependia do apoio das classes comerciais e usava principalmente o laissez-faire e o livre comércio como seus métodos. O outro foi o princípio da proteção social, cuja finalidade era preservar o homem e a natureza, além da organização produtiva, e que dependia do apoio daqueles mais imediatamente afetados pela ação 
deletéria do mercado - básica, mas não exclusivamente, as classes trabalhadores e fundiárias - e que utilizava uma legislação protetora, associaçóes restritivas e outros instrumentos de intervenção com seus métodos.

Destarte, se de um lado o paradigma do mercado autorregulável se expandia, de outro cresciam as críticas e as pressóes contra o pauperismo das massas, que cada vez mais "ganhavam adeptos e forneciam elementos que justificavam, já no século 19, a introdução de medidas pontuais de proteção social, ao arrepio dos princípios liberais" (PEREIRA, 2008, p. 81). E em resposta às pressóes dos trabalhadores, que tinham suas condiçóes de vida deterioradas, foram lançadas no final do século 19, no governo alemão de Otto Von Bismarck, as bases da seguridade social, que inclui, entre outros, os serviços de saúde.

No modelo bismarckiano, somente os trabalhadores e suas famílias podiam usufruir dos benefícios da seguridade social, uma vez que o acesso condicionado a uma contribuição direta anterior (descontada nas folhas de pagamento dos salários) e o montante das prestaçóes era proporcional à contribuição efetuada. $\mathrm{O}$ modelo era, portanto, uma espécie de seguro social, que, apesar de representar um avanço na prestaçáo de serviços sociais pelo Estado quando comparado com a Lei dos Pobres de 1834, deixava parte da população fora da cobertura da seguridade social.

O ápice do princípio da proteção social somente foi alcançado após a Segunda Guerra, quando o capitalismo, diante do quadro de instabilidade política, social e econômica mundial, precisou se reinventar. Em prol da manutenção do modo capitalista, acolheu-se demandas por maior igualdade e reconhecimento dos direitos sociais e segurança econômica, forjando-se um novo modelo de organização estatal - o Estado de Bem-Estar Social - que, ancorando-se nos conceitos de seguridade e cidadania social, assumiu o papel de prover serviços sociais, na condição de direito assegurado pelo Estado e de dimensóes quase universais.

Um dos pilares do Welfare State foi o Plano Beveridge que, formulado durante a Segunda Guerra Mundial na Inglaterra, propôs uma revisão completa do sistema de proteção social inglês, mudando o objetivo dessas políticas, vale dizer, substituindo o escopo de proteção dos trabalhadores contra as situaçóes de risco por um objetivo maior: o combate à pobreza. 
No sistema beveridgiano, os direitos sociais passaram a ter caráter universal, destinados incondicionalmente a todos os cidadãos, a fim de garantir a todos que se encontravam em condiçôes de necessidade os mínimos sociais. Conforme Pereira (2008, p. 122-123):

\begin{abstract}
A partir daí, os mínimos sociais passaram a ter uma conotação mais alargada, incluindo, além de políticas de manutenção de renda - geralmente sob a forma de uma rede de segurança impeditiva do resvalo de cidadãos social e economicamente vulneráveis para baixo de uma linha de pobreza legitimada pela sociedade - outros mecanismos adicionais de proteçáo social, como: serviços sociais universais (saúde e educação, por exemplo), proteção ao trabalho (em apoio ao pleno emprego) e garantia do direito ao acesso a esses bens e serviços e ao seu usufruto. Esta foi a fase de ouro das políticas de proteção social, na qual a otimização da satisfação das necessidades humanas básicas tornou-se uma tendência promissora, a partir da Europa.
\end{abstract}

Segundo Pereira (2008, p. 93), portanto, em que pesem as críticas que podem ser feitas à ideia de mínimos sociais, "o Sistema de Seguridade Social de Beverigde inovou, de fato, por ser nacional e unificado e conter um eixo distributivo, ao lado do contributivo, além de abolir os testes de meio no âmbito da assistência social".

A prestação dos bens e serviços sociais não envolvia mais a discussão da necessidade (marca das primeiras políticas sociais inglesas que se destinavam àqueles que não poderiam participar do processo produtivo) e tampouco pautava-se na base contributiva de cada indivíduo (vale dizer, no quanto cada trabalhador havia contribuído para o serviço).

No Estado de Bem-Estar Social cabia ao Estado, conforme Marshall (1967, p. 93), garantir "um mínimo de certos bens e serviços essenciais (tais como assistência médica, moradia, educação, ou uma renda nominal mínima ou salário mínimo) a ser gasto em bens e serviços essenciais". É nesse momento que os direitos sociais se inserem no status da cidadania, passando a provisão de serviços sociais a ser vista como direito de cidadania, que deveria ser assegurada a todos os indivíduos independentemente de se situarem nos grupos críticos e da sua inserção no mercado de trabalho. 
Dessa forma, como contrapartida ao direito dos indivíduos, exsurgiu o dever do Estado de regulamentar um conjunto de garantias aos cidadãos em situação de fragilidade e infortúnio social. Pereira (2008, p. 88-89) afirma que no Welfare State,

[...] Estado e mercado se articularam e se co-responsabilizaram pela formulaçáo e gerenciamento de políticas favorecedora de pleno emprego e de um conjunto de benefícios e serviços que, na perspectiva dos direitos, asseguravam aceitáveis padrôes de vida aos cidadãos, a saber: o seguro social obrigatório, leis de proteção ao trabalho, salários mínimos, ampliação de instituições e serviços de saúde e educaçẫo, programas de habitação subsidiados [...] No âmbito das modernas estruturas do Estado de Bem-Estar firmaram-se vigorosas forças sindicais, instituíram-se, expandiram-se e multiplicaram-se direitos de cidadania e fortaleceram-se instituições democráticas.

Como pode-se constatar, o Estado de Bem-Estar tem como núcleo central a seguridade social. Por essa razão, foi somente a partir deste modelo que a saúde do indivíduo entrou na agenda pública. Antes disso, no Estado Liberal, o poder público agia tão somente no âmbito da saúde coletiva, a fim de oferecer saneamento e evitar epidemias, tendo em vista que o acesso aos serviços médicos era condicionado à possibilidade de quem poderia pagar por eles (AÑÓN, 2009). Como grande parte da população não dispunha dos recursos necessários para custear as prestaçôes sanitárias, poucos eram os que tinham acesso aos cuidados médicos, os quais, como referido anteriormente, eram quase que restritos aos trabalhadores e suas famílias.

Com o Plano Beveridge, instituiu-se um modelo de Sistema Nacional de Saúde não contributivo, universal e financiado pelos impostos. O direito à saúde passou, entáo, a ser titularizado por todos os indivíduos, que podiam se valer do Sistema Nacional sem qualquer contraprestação pecuniária e independente da comprovação da necessidade social. As bases da seguridade social foram modificadas. 
Añón (2009, p. 24) afirma que uma característica das políticas do Estado de Bem-Estar Social "foi a participação do Estado na promoção e proteção da saúde da população, mediante a ampliação de sistemas públicos de saúde e pelo progressivo reconhecimento e positivação do direito à saúde" ${ }^{1}$ E é em razão do movimento estatal de maior proteção à saúde que, segundo Dallari (1995, p. 25):

No início do século XX se encontra instaurada a proteção sanitária como política de governo. E são hierarquizadas três formas, hoje clássicas de prevenção: a primária, que se preocupa com a eliminaçáo das causas de condiçóes de aparecimento das doenças, agindo sobre o ambiente (segurança nas estradas, saneamento básico, por exemplo) ou sobre o comportamento individual (exercício e dieta, por exemplo); a secundária ou prevenção específica, que busca impedir o aparecimento de doença determinada, por meio da vacinação, dos controles de saúde, da despistagem; e a terciária, que visa limitar a prevalência de incapacidades crônicas ou de recidivas (LEAVELL; CLARK, 1976). ${ }^{2} \mathrm{O}$ Estado do bem-estar social da segunda metade do século XX reforça a lógica econômica, especialmente em decorrência da evidente interdependência entre as condições de saúde e de trabalho, responsabilizando-se pela implementação da prevenção sanitária.

Instituem-se, então, os sistemas de previdência social, que não se limitam a cuidar dos doentes, mas organizam a prevençáo sanitária. A princípio, pressupunham uma diferenciação entre assistência social, destinada às classes mais desfavorecidas e baseada no princípio de solidariedade e, portanto, financiada por fundos públicos estatais, e previdência social, mecanismo assecuratório restrito aos trabalhadores. Entretanto, exatamente porque a prevenção sanitária era um dos objetivos do desenvolvimento do Estado, logo se esclarece o conceito de seguridade social, que engloba os subsistemas de assistência, previdência e saúde públicas. Trata-se, portanto, de identificar a responsabilidade a priori do Estado. Assim, quanto aos estilos de vida, verifica-se um grande investimento estatal.

1 Tradução livre do trecho: “[...] ha sido la participación del Estado en la promoción y protección de la salud de la población, mediante la extensión de sistemas públicos de salud y mediante el progresivo reconocimiento y positivación de um derecho a la salud".

2 Citação do próprio texto de Dallari (1995, p. 25). 
À saúde foi conferida importância não somente no âmbito dos Estados, mas também no contexto internacional. Em 1946 foi criado um organismo específico para a sua proteção e promoção, a Organização Mundial da Saúde (OMS), que teve como objetivo promover a aquisição, por todos os povos, do nível de saúde mais elevado possível.

A Declaração Universal dos Direitos Humanos de 1948 também consagrou a saúde como direito humano essencial, prevendo que todo indivíduo tem direito a um padrão de vida capaz de assegurar a si e a sua família saúde e bem-estar, alimentação, vestuário, habitação, cuidados médicos e os serviços sociais indispensáveis.

O Pacto Internacional de Direitos Econômicos, Sociais e Culturais, por sua vez, realça que os Estados signatários reconhecem o direito de todos à fruição do mais alto nível de saúde física e mental. Eleva-se em âmbito internacional a questão acerca do significado da saúde, tema que, ao longo dos anos, tem suscitado inúmeras controvérsias e discussóes.

O presente trabalho filia-se à conceituação adotada pela OMS, que no preâmbulo de sua Constituição define a saúde como o "estado completo de bem-estar físico, mental e social e não meramente a ausência de doença ou enfermidade" (ORGANIZAÇÃO..., 1946, p. 22).

Essa conceituação realça o caráter complexo e multifacetado da saúde, que náo pode ser compreendida apenas como ausência de doenças, apesar de esta ser um elemento central, uma vez que "afirma a existência de um núcleo preciso, orientando a compreensão do que, de forma clara e inquestionável, é direito subjetivo do indivíduo, ou seja, o da assistência integral, quer para tratar, quer para ainda readequar o indivíduo socialmente" (DALLARI; NUNES JÚNIOR, 2010, p. 10).

A saúde, no entanto, é mais que isso, indo além da assistência médica e das açóes para a promoção e manutenção de um estado saudável. Ela está relacionada com as próprias condiçóes de vida das pessoas: meio ambiente, saneamento básico, moradia, alimentação, educação, trabalho, entre outros. 
Assim, o direito à saúde "parece não ser suscetível de uma consideração simplista, apresentando-se mais como um direito complexo, isso porque agrupa uma série de direitos diversos, ou porque se desdobra em uma série de elementos de diferente alcance"3 (AÑÓN, 2009, p. 41).

Nesse desiderato, o direito à saúde náo pode ser compreendido na dimensão puramente individual, no sentido de que ser saudável depende tão somente do indivíduo. Ao contrário, envolve uma série de fatores individuais e coletivos, mostrando-se a um só tempo direito individual e social. É individual porque envolve o direito de não sofrer violaçôes por parte de terceiros e do Estado e social por exigir do governo a prestação de serviços públicos para a prevenção de doenças e para a promoção, proteção e recuperação da saúde.

O direito à saúde é também um bem coletivo, exigindo a participação da sociedade e do Estado na sua promoção, conforme bem realçado na Constituição da Organização Mundial da Saúde (1946, p. 2):

A saúde de todos os povos é fundamental para se alcançar a paz e a segurança e depende da mais ampla cooperação de indivíduos e Estados.

Os resultados alcançados por qualquer Estado na promoção e proteçáo da saúde são valiosos para todos.

A desigualdade dos diferentes países na promoção da saúde e no controle das doenças, especialmente as transmissíveis, constitui um perigo comum. $[\ldots]$

Os governos têm responsabilidade na saúde de seus povos, a qual só pode ser integralmente cumprida mediante a adoção de medidas sanitárias e sociais adequadas.

Assim sendo, no texto normativo da OMS, ao Estado e à sociedade é conferido o dever de criar condiçôes econômicas, políticas e sociais para a promoção e proteção da saúde dos indivíduos. Esse aspecto é importante, na medida em que

3 Tradução livre do trecho: "parece no ser suscetible de una consideración simplista y más bien se aparece como um derecho complejo, bien porque agrupa una serie de derechos diversos, o bien porque se despliegue en una serie de elementos de alcance diferente" 
a saúde depende não apenas de aspectos pessoais (predisposição genética, características físicas, hábitos, etc.), mas também das condições de vida que a sociedade e, em especial, o poder público, proporcionam ao indivíduo.

A Constituição da OMS ressalta, também, a necessidade da comunhão de esforços dos Estados para efetivação do direito à saúde. Isso deve-se ao fato de que, no mundo globalizado, o intenso fluxo de pessoas e mercadorias também favorece a difusão e propagação de doenças, de forma que o combate só será eficaz se todos empreenderem esforços para o alcance de um nível de desenvolvimento semelhante na proteção da saúde e no combate às doenças, isso porque "a extensão a todos os povos dos benefícios dos conhecimentos médicos, psicológicos e afins é essencial para a mais ampla realização da saúde" (ORGANIZAÇÃO..., 1946).

Como se vê, a Constituição da OMS, além de conceituar a saúde, apresenta muitos aspectos a ela relacionados, constituindo um marco normativo muito importante para o estudo do tema, apesar das críticas que são feitas em virtude da suposta amplitude do texto. Añón (2009, p. 49-50) observa que:

Apesar de todos os inconvenientes, o conceito de saúde da OMS tem, frente às concepçóes anteriores de saúde, a vantagem de enfatizar determinados aspectos que não devem ser esquecidos, apresentando a novidade do abandono da visão puramente medicamentalizada: a proteção e promoção da saúde não é unicamente uma questáo médica e tampouco limitada à assistência sanitária, uma vez que há outros esforços e políticas públicas que podem contribuir em grande medida com este objetivo. Assim, essa concepção integra a proteção da saúde em um marco geral, reconhecendo o seu duplo caráter individual e social (isto é, ainda que em última instância a saúde se refira à saúde dos indivíduos, existem fatores que são sociais - e o que talvez seja o mais importante, modificáveis que incidem na mesma). Com isso, entende-se que a saúde implica também a existência de condiçôes para o desenvolvimento das pessoas, sendo inseparável da paz, da eliminação da pobreza, da redução do desemprego, da preservação do meio ambiente, etc. Significa a existência de uma correlação entre saúde das pessoas e o desenvolvimento socioeconômico. Esta concepçáo se opóe à que 
se baseia na oposição saúde/enfermidade. E, além disso, neste sentido, parece frisar a possibilidade de ser guiada por estratégias não meramente curativas, mas também por estratégias amplas de promoção da saúde. ${ }^{4}$

Destaca-se que a proteção e a promoção da saúde não podem ser reduzidas a uma questão exclusivamente médica, assim como não podem ser limitadas à assistência à saúde, pois exigem do Estado outros esforços e políticas públicas que contribuam para a real efetivação do direito à saúde. Assim, a concepção da OMS integra a ideia de proteção da saúde num contexto geral, reconhecendo seu duplo caráter: individual e social (RAMOS, 2014).

A partir da análise desse conceito entende-se que a saúde implica também a existência de condiçóes para o desenvolvimento das pessoas, bem como torna-se imprescindível a redução da violência, a eliminação da pobreza, a redução de desemprego, a conservação de meio ambiente, entre outras questóes socioeconômicas (RAMOS, 2014).

O texto normativo da OMS é, portanto, referência obrigatória para a compreensão dos principais aspectos relacionados à saúde: conceito e complexidade; indissociabilidade das condiçôes de vida das pessoas; caráter individual, social e coletivo e a necessidade da participação da sociedade e do Estado na sua garantia.

4 Tradução livre do trecho: "A pesar de todos los inconvenientes, el concepto de salud de la OMS tiene unas ventajas y enfatiza determinados aspectos que non deben ser olvidados, frente a anteriores concepciones de la salud, presenta la novedad de abandonar la visión puramente medicalizada: proteger y promover la salud no es únicamente una cuestión médica ni limitada a la asistencia sanitária, sino que hay otros esfuerzos y políticas públicas que pueden contribuir en gran medida a este objetivo. Así, esta concepción integra la proteción de la salud en un marco general, recogiendo su doble cara individual y social (es decir, aunque en última instancia la salud se refiere a la salud de os indivíduos, existen factores que son sociales - y lo que quizá sea más importante, modificables - que inciden en la misma). Con ello, se entiende que la salud implica también la existência de uns condiciones para el desarrollo de las personas y que resulta inseparable de la paz, la eliminación de la pobreza, la reducción del desempleo, la conservación del medio ambiente, etc. Significa atender a la existencia de una correlación entre la salud de las personas e el desarrollo socioeconómico. Esta concepción se opone a la que se basa en la oposición salud/enfermedad, y que entiende simplesmente la salud como ausencia de enfermedad. Y además, en este sentido, parece poner la vista en la posibilidad de guiarse por estrategias no meramente curativas, sino también amplias como la promoción de la salud". 


\section{DIREITO À SAÚDE NO BRASIL}

Verifica-se que tal concepção ampla do direito à saúde é algo recente na história brasileira, não existindo na vigência dos ordenamentos constitucionais brasileiros anteriores. Partindo de uma compreensão do direito à saúde como mera benesse estatal vigente na fase imperial e passando pelo modelo de seguro social ligado ao mercado formal de trabalho adotado no início do século 20 (ASENSI, 2013), o direito à saúde assegurado na atual ordem constitucional brasileira representa a busca por uma sociedade igualitária e democrática, na qual a população deve ter asseguradas as condiçóes para o exercício de seus direitos constitucionais (RAMOS; MIRANDA NETTO, 2017)

A Constituição Federal de 1988 foi o primeiro texto constitucional brasileiro a tratar a saúde como direito, inserindo-a no sistema da seguridade social, que, por sua vez, "compreende um conjunto integrado de açóes de iniciativa dos poderes públicos e da sociedade, destinadas a assegurar os direitos relativos à saúde, à previdência e à assistência social" (artigo 194) (BRASIL, 1988).

Ao contrário da previdência (de caráter contributivo) e da assistência social (prestada a quem está em situação de necessidade), a saúde pauta-se pelo acesso universal, estando prevista como "direito de todos e dever do Estado, garantido mediante políticas sociais e econômicas que visem à redução do risco de doença e de outros agravos e ao acesso universal e igualitário às açóes e serviços para sua promoção, proteção e recuperação" (CF, artigo 196). Souza (2013, p. 206-207) realça que

[...] O mencionado dispositivo é o cerne do maior número de questôes enfrentadas pelo operador jurídico que se depara com lides envolvendo a temática, gerando constantes tensóes institucionais diante da pródiga interpretação que geralmente a ele é atribuída pelo Judiciário e da postura mais restritiva da Administração e dos gestores da saúde, premidos pelas limitações orçamentárias. 
Vale realçar que a saúde está prevista, ainda, no artigo $6^{\circ}$ do texto constitucional, isto é, no rol dos direitos fundamentais sociais. Apesar, no entanto, de ser um direito social, o direito à saúde possui também uma dimensão subjetiva individual, sendo a um só tempo, portanto, um direito de viés programático e um direito oponível ao Estado judicialmente.

Na primeira parte do artigo 196 pode-se perceber a institucionalização de um conceito amplo de saúde, incorporando-se ao contexto brasileiro a compreensão de saúde defendida desde 1948 pela Organizaçáo Mundial da Saúde, que, como visto, conceitua a saúde náo apenas como a ausência de doença ou enfermidade, mas como um estado de completo bem-estar físico e social.

Dessa forma, a Constituição, ao preceituar que a saúde deve ser garantida mediante políticas sociais e econômicas que visem à redução do risco de doença e de outros agravos, abandonou o entendimento puramente biológico da saúde que dominava as açóes estatais na área, mais voltadas, até então, para a prevenção e o tratamento das doenças contagiosas. Segundo Santos (2010, p. 150):

O primeiro enunciado do artigo - execução de políticas sociais e econômicas protetoras da saúde - vincula-se a planos e programas do Estado nacional, que devem assegurar ao indivíduo e à coletividade tudo aquilo que possa ser considerado essencial para a satisfação da saúde física, mental, psicológica, moral e social: morar bem, ter salário digno, ter mais lazer, boa educação, alimentação suficiente, segurança, previdência, etc.

A saúde passou, assim, a náo ser mais considerada de forma isolada, vale dizer, na condição de fenômeno relacionado somente ao homem, ao seu corpo e suas determinaçóes genéticas. Albergou-se também no conceito de saúde a relaçáo do indivíduo com o ambiente social que o rodeia.

Nessa nova concepção, a saúde está interligada com o próprio modo de vida das pessoas, exigindo-se para a sua efetivação a garantia de: trabalho em condiçóes apropriadas; alimentação para todos; moradia higiênica e digna; educação e informaçáo plena; qualidade do meio ambiente; transporte seguro e acessível; repouso, lazer e segurança; direito à liberdade, à livre organizaçáo e expressão e acesso universal e igualitário aos serviços setoriais em todos os níveis. 
Em razão da correlação da saúde com fatores sociais, ambientais, econômicos e educacionais, a elaboração e execução das políticas sociais e econômicas protetoras da saúde não ficam restritas apenas ao sistema de saúde criado pela Constituição de 1988, envolvendo também outras pastas de governo, que devem trabalhar para "garantir às pessoas e à coletividade condiçóes de bem-estar físico, mental e social", mediante a promoçáo do acesso à alimentação, moradia, saneamento básico, meio ambiente, trabalho, renda, educação, atividade física, transporte, lazer e outros bens e serviços essenciais (Lei 8.080/90, artigo 30).

É o prescrito na segunda parte do artigo 196 - a promoção do acesso universal e igualitário às açóes e serviços para a promoção, proteção e recuperação da saúde - que se dirige mais especificamente ao sistema de saúde inaugurado pela ordem constitucional atual, qual seja: o Sistema Único de Saúde (SUS).

A Constituição de 1988 conceitua o SUS como uma rede regionalizada e hierarquizada de açóes e serviços públicos de saúde (artigo 198), traça algumas de suas diretrizes (artigo 198 I a III) e atribuiçôes (artigo 200), fixa parâmetros de financiamento do sistema (artigo $198 \$ \$ 1^{\circ}$ a $3^{\circ}$ ) e permite a atuação da iniciativa privada de forma complementar (artigo 199).

Antes da criação do SUS, as açôes e serviços de saúde eram divididos entre o Ministério da Saúde e o Ministério da Previdência e Assistência Social. O primeiro responsabilizava-se pelas açóes preventivas e de caráter coletivo, enquanto o segundo cuidava da assistência médica, de caráter curativo, que era assegurada somente aos trabalhadores contribuintes da Previdência.

Durante a ditadura militar, a sociedade brasileira deparou-se com um modelo de proteção social por parte poder público que excluía a população de toda e qualquer participação política na gestão do sistema sanitário. Este modelo tornava os trabalhadores meros financiadores do Instituto Nacional de Previdência Social (INPS) após a centralização da previdência social ocorrida em 1966 e o consequente alargamento do poder de controle do governo autoritário sobre a sociedade (RAMOS; MADUREIRA; SENA, 2013).

Para tanto, conforme descrito anteriormente, houve a unificação das diferentes entidades de previdência até entáo existentes, resultando no denominado Instituto Nacional de Previdência Social (INPS). Posteriormente, graças à crescente 
complexidade desse sistema de saúde previdenciário e da necessidade de celebração de contratos com clínicas e hospitais da iniciativa privada para a efetiva prestação de serviços - gerando um consequente dever de fiscalização da estrutura burocrática daí resultante - foi criado, a partir do INPS, o Instituto Nacional de Assistência Médica da Previdência Social (Inamps) enquanto estrutura administrativa própria (POLIGNANO, 2001).

Estava-se diante da consolidação do modelo de proteção social em saúde do tipo seguro social (GIOVANELLA et al., 2012), surgido no Brasil ainda no início do século 20, com o governo central unificando os diversos institutos provedores dos serviços de Previdência Social e saúde antes divididos por categorias profissionais. Nesse sentido, Ramos, Madureira e Sena (2013) afirmam que:

Duas particularidades fundamentais que impuseram a unificação da Previdência Social (com a junção dos IAPs em 1966) podem ser expressas no aumento da interferência do Estado na sociedade e no afastamento dos trabalhadores da cena política. Nesta perspectiva, observa-se a exclusão popular da gestão da previdência (os trabalhadores tornaram-se meros financiadores da previdência) (p. 55).

Diferentemente dos atuais princípios da universalidade e da integralidade do atendimento, o governo militar restringia seu papel no setor da saúde pública somente a medidas de natureza preventiva e a atividades epidemiológicas e de vigilância sanitária. Apenas a parcela da populaçáo que estivesse inserida no mercado formal de trabalho, vinculando, assim, a Previdência Social - de caráter contributivo - estaria amparada pelos serviços privados de saúde, que eram custeados e fiscalizados pelo Inamps. As atividades de cunho assistencialista - e não contributivo - permaneciam sendo prestadas pelas instituiçóes de caridade.

A partir da Constituição de 1988 decidiu-se pela expansão e fortalecimento do setor público, bem como pela separação da saúde da previdência social. Com o SUS, os serviços e ações de saúde passaram a ser organizados em uma rede única, de acesso universal, isto é, a fruição dos serviços da rede independe de contribuição para o sistema. Souza (2013, p. 207, grifo nosso) expressa que: 
O art. 198 é a matriz constitucional do sistema único de saúde, o SUS, rede regionalizada e hierarquizada de açóes e serviços públicos de saúde que constituem um sistema único, organizado de acordo com as diretrizes da descentralização, com direção única em cada esfera de governo; do atendimento integral, com prioridade para as atividades preventivas, sem prejuízo dos serviços assistenciais e da participação da comunidade, sistema este responsável pelo oferecimento de mais de $75 \%$ da assistência à saúde da população brasileira.

Em 1990 foi promulgada a Lei 8.080, conhecida como a Lei Orgânica de Saúde, com o fim de regulamentar os dispositivos constitucionais explicitados, de modo a criar condiçóes para a promoção, proteção e recuperação da saúde, a organização e o funcionamento dos serviços correspondentes.

O Sistema Único de Saúde é constituído, nos termos da Lei 8.080/90, pelo "conjunto de açóes e serviços de saúde, prestados por órgáos e instituiçóes públicas federais, estaduais e municipais, da administração direta e indireta e das fundaçóes mantidas pelo poder público". A iniciativa privada (preferencialmente as entidades filantrópicas e sem fins lucrativos) também poderá integrar o SUS em caráter complementar, quando a disponibilidade dos serviços públicos for insuficiente para garantir o acesso e a integralidade da assistência aos cidadáos, desde que sejam mantidos os princípios do sistema e mediante contrato de direito público ou convênio (AGUIAR, 2011).

No artigo $7^{\circ}$ da Lei 8.080/90 estão previstos os seguintes princípios norteadores dos serviços e açóes de promoção, proteção e recuperação da saúde: universalidade de acesso aos serviços de saúde; integralidade de assistência; preservação da autonomia das pessoas na defesa de sua integridade física e moral; igualdade da assistência à saúde, sem preconceitos ou privilégios de qualquer espécie; direito à informação; utilização da epidemiologia para o estabelecimento de prioridades, a alocação de recursos e a orientação programática; participação social; descentralização político-administrativa, com direção única em cada esfera de governo; integração em âmbito executivo das ações de saúde, meio ambiente e saneamento básico; conjugação dos recursos financeiros, tecnológicos, materiais e humanos dos entes federados; capacidade de resolução dos serviços em todos os níveis de assistência e organização dos serviços públicos de modo a evitar duplicidade de meios para fins idênticos. 
Sobre as diretrizes do SUS, é importante tecer maiores consideraçóes sobre: a universalidade, igualdade, integralidade, unidade, descentralização e hierarquização.

O princípio constitucional da universalidade decorre do próprio caráter de direito fundamental que foi atribuído à saúde a partir do ordenamento de 1988. $\mathrm{O}$ direito à saúde aparece, portanto, como "um elemento intrínseco à dignidade do ser humano" (DALLARI; NUNES JÚNIOR, 2010, p. 72) e, por isso, pode ser exigido por todos os cidadáos.

Desse modo, a assistência médica era de responsabilidade do Ministério de Previdência e Assistência Social, prestada por meio do Instituto Nacional de Assistência Médica da Previdência Social (Inamps) aos trabalhadores ou aos contribuintes autônomos do Instituto. As pessoas que estavam excluídas do mercado de trabalho ou que não podiam pagar as contribuiçôes ao Inamps estavam excluídas das prestaçóes estatais de saúde. Em caso de doença, pagavam pelos serviços privados ou recorriam às instituiçóes filantrópicas.

A Constituição de 1988 inseriu a saúde no capítulo da seguridade social, juntamente com a previdência e a assistência social, no entanto a saúde pauta-se em princípios e diretrizes totalmente diferentes das observadas nas demais esferas. Enquanto a previdência tem caráter contributivo e a assistência social somente é prestada aos necessitados, a saúde tem acesso universal, devendo os serviços de prevenção e de assistência ser assegurados pelo Estado a toda a população. Dessa forma, conforme Weichert (2004, p. 158):

[...] O Sistema Único de Saúde não foi formulado apenas para a população carente (como uma política de assistência social) ou para os que contribuem à seguridade social (como uma prestação previdenciária), mas sim para a garantia de saúde a todos que necessitarem e desejarem a ele (o sistema público) recorrer [...].

Além do acesso universal, a Carta Magna previu o acesso igualitário aos serviços de saúde, o que significa que o acesso será assegurado a todos, sem distinçôes e privilégios. A adoção do princípio da igualdade nos serviços e açóes de saúde nada mais é do que a concretização, que deve ocorrer na prestação de qualquer serviço público, da noção de igualdade refletida no caput do artigo $5^{\circ} \mathrm{da} \mathrm{CF}$ e do princípio republicano insculpido no artigo 19 III do texto constitucional, que 
veda a criação de distinções ou preferências entre brasileiros. Tal princípio pode ser sintetizado pela máxima segundo a qual a mesma situação clínica deve merecer a mesma atenção em saúde.

Serrano (2009, p. 76) adverte que "a conjugação dos princípios da universalidade e da igualdade acaba dando lugar à eqüidade”, que significa que devem ser reconhecidas as desigualdades na mortalidade e incidência de doenças entre os diferentes grupos sociais, de modo que as açôes de saúde possam focar nos indivíduos mais vulneráveis (crianças, idosos, mulheres, etc.), sem que isso represente afronta à igualdade preconizada no artigo $5^{\circ} \mathrm{da} \mathrm{CF}$.

Outro princípio elencado no artigo $7^{\circ}$ da Constituição Federal é o da integralidade, que, para Carvalho (2006), possui duas dimensões: horizontal e vertical. A primeira exige que haja a interligação de serviços de prevenção e tratamento, em âmbito individual e coletivo, devendo ser prestados em todos os níveis de complexidade. Já a dimensão vertical está relacionada ao conceito amplo de saúde, pressupondo "um olhar para as questôes que envolvem o afetivo, o biológico, o espiritual, o sociocultural, entre outras" (2006, p. 16).

O princípio da unidade, por sua vez, traduz o objetivo do Sistema Único de Saúde de "articular todos os serviços existentes no país para que, atuando de forma ordenada, possa haver a otimizaçáo dos escassos recursos sociais em todos os níveis da Federação, propiciando ganho de escala e evitando a sobreposição de estruturas" (SOUZA, 2013, p. 209).

É o princípio da unidade que permite ao cidadão recorrer, na falta dos serviços em sua localidade, aos serviços de saúde de municípios ou Estados vizinhos, bem como impede a "instrumentalização do sistema único pelo privado, proibindo que o paciente recorra ao sistema público exclusivamente para obter medicamentos, exames clínicos e tratamentos cirúrgicos prescritos por médico particular" (SOUZA, 2013, p. 210).

A descentralização, também, é um princípio organizativo do SUS, entendido como uma redistribuição de responsabilidades e recursos entre as três esferas de governo, com ênfase na municipalização, isto é, o município é o principal responsável 
pela garantia da saúde da população, somente podendo ser atribuídos aos Estados e à União os serviços que os municípios não possam prestar, ou que tenham uma dimensão regional e nacional. Conforme Souza (2013, p. 213):

[...] Aqui se insere a acirrada discussão sobre a modalidade de responsabilidade dos entes federados, não nos parecendo ser o melhor entendimento aquele que prega a responsabilidade solidária indiscriminadamente entre a União, os Estados e os municípios. Isso porque, a uma, a desconsideração das divisōes de competências e responsabilidades estabelecidas nos atos normativos secundários e nas leis reguladores da matéria funcionam contra a diretriz da descentralizaçáo (objetivo historicamente perseguido pelo Movimento de Reforma Sanitária e pelo constituinte como melhor caminho para a melhoria global do sistema de saúde); e, a dois, porque a condenação incidente sobre diversos entes da federaçáo gera desperdício de recursos em um ambiente já suficientemente marcado pela escassez.

A regionalização refere-se à forma de organização do sistema de saúde por circunscriçóes territoriais (de modo a levar-se em consideração o dinamismo e a complexidade dos perfis epidemiológicos locais), enquanto o princípio da hierarquização indica a necessidade de organizar o sistema por níveis de complexidade crescentes: primário (pequena complexidade - ex.: consultas e curativos), secundário (média complexidade - ex.: pequenas cirurgias) e terciário (alta complexidade - ex.: cirurgias mais complexas).

As diretrizes da regionalização e da hierarquização possuem dois corolários: i) o estabelecimento de um sistema de atendimento afunilado, induzindo o usuário a ter o contato inicial com o nível primário de atendimento (a grande porta de entrada do sistema) para que a partir daí possa ser encaminhado aos níveis mais complexos (que possuem demanda decrescente e custo crescente em relação ao nível primário); e ii) o oferecimento seletivo de "[...] níveis de atendimento secundário e terciário em centros regionais capazes de atender à demanda de vários pequenos municípios, priorizando a alocação de recursos no nível primário de atendimento" (SOUZA, 2013, p. 211). 
Todas essas diretrizes do SUS, estabelecidas na Constituição Federal e na Lei Orgânica da Saúde, são importantes marcos para a concretização do direito à saúde, vale dizer, para, diante da sua complexidade e multiplicidade de prestaçóes, especificar o seu âmbito de abrangência, ou, pelo menos, aquilo que o direito à saúde não comporta.

Dessa forma, faz-se necessário observar, por exemplo, que os ditames dos princípios da unidade, descentralização, hierarquia e regionalização do SUS são violados diante de determinadas decisóes judiciais, como as que estabelecem o dispêndio de recursos públicos para o custeio de remédios, tratamentos e procedimentos prescritos exclusivamente por profissionais que náo pertenciam aos quadros do sistema público; as que são proferidas sem a análise minuciosa dos atos normativos de repartiçáo de competência e responsabilidade e as que condenam os municípios ao fornecimento de serviços de alta complexidade ou bens de alto custo. É importante realçar que a defesa da universalidade do direito à saúde não significa que toda e qualquer pretensão de bens ou serviços de saúde deva ser concedida pelo poder Judiciário. É preciso haver uma racionalidade.

\section{CONSIDERAÇÕES FINAIS}

Destacou-se que o ápice do princípio da proteção social somente foi alcançado após a Segunda Guerra Mundial, quando o capitalismo, diante do quadro de instabilidade política, social e econômica mundial, precisou se reinventar, fundamentalmente pela necessidade de sua própria manutenção. Acabou por acolher demandas por maior igualdade, reconhecimento dos direitos sociais e segurança econômica, elementos decisivos no processo de constituição do Estado de Bem-Estar Social.

Constatou-se que no Estado de Bem-Estar Social cabe ao poder público, na concepção de Marshall (1967), a garantia de mínimos sociais e por conseguinte de direitos sociais que passam a estar inseridos no status da cidadania. Por sua vez, verificou-se que a seguridade social passou a ser o núcleo desse modelo de Estado; por essa razão, foi somente a partir desse arquétipo organizacional que a saúde do indivíduo entrou na agenda pública como direito fundamental social. 
Destacou-se que, no final da primeira metade do século 20, à saúde foi conferida importância não somente no âmbito dos Estados, mas também no contexto internacional. Essa afirmação pode ser constatada com a criaçáo de um organismo específico para a sua proteção e promoção, ou seja, a Organização Mundial da Saúde - OMS (1946), organismo que se estabeleceu com objetivo de promover a aquisição, por todos os povos, do nível de saúde mais elevado possível.

Evidenciou-se que no Brasil, a Constituição Federal de 1988 foi um marco decisivo na afirmaçáo do direito à saúde, inserto em capítulo dirigido à seguridade social. Demonstrou-se que o direito à saúde está em condição diversa da previdência e da assistência sociais, na medida em que se funda nos princípios da igualdade e universalidade. Destacou-se, por conseguinte, a criaçáo do Sistema Único de Saúde - SUS - que representou uma etapa peremptória no processo de conquistas e efetivação do direito à saúde.

Por fim, ressaltou-se que o conteúdo do direito à saúde não se resume a uma perspectiva biológica, condensada meramente na ideia de ausência de doença, na verdade está vinculado aos aspectos próprios do modo de vida das pessoas, exigindo-se para a sua efetivação a garantia de outros direitos fundamentais, quais sejam: trabalho em condições adequadas; alimentação para todos; moradia higiênica e digna; educação e informação plenas; qualidade do meio ambiente; transporte seguro e acessível; repouso, lazer e segurança; direito à liberdade, à livre organização e expressão e acesso universal e igualitário aos serviços setoriais em todos os níveis.

\section{REFERÊNCIAS}

AGUIAR, Z. N. SUS: Sistema Único de Saúde - Antecedentes, percurso, perspectivas e desafios. São Paulo: Editora Martinari, 2011.

AÑÓN, Carlos Lena. Salud, justicia, derechos: el derecho a la salud como derecho social. Madri: Dyknson, 2009.

ASENSI, Felipe Dutra. Direito à saúde: práticas sociais reivindicatórias e sua efetivação. Curitiba: Juruá, 2013.

BRASIL. Constituição da República Federativa do Brasil de 1988. Disponível em: <http:// www.planalto.gov.br/ccivil_03/constituicao/constituicao.htm>. Acesso em: 5 fev. 2015. 
BRASIL. Lei 8.080, de 19 de setembro de 1990. Disponível em: <http://www.planalto.gov. br/ccivil_03/leis/18080.htm>. Acesso em: 5 fev. 2015.

CARVALHO, Gilson. Os governos trincam e truncam o conceito da integralidade. Radis, Rio de Janeiro, n. 49, ago. 2006. Disponível em:<http://www6.ensp.fiocruz.br/radis/revista-radis/49/reportagens/“os-governos-trincam-e-truncam-o-conceito-da-integralidade $>$. Acesso em: 12 maio 2015.

DALLARI, Sueli Gandolf. Os estados brasileiros e o direito à saúde. Sáo Paulo: Hucitec, 1995.

DALLARI, Sueli Gandolf; NUNES JÚNIOR, Vidal Serrano. Direito sanitário. São Paulo: Verbatim, 2010.

GIOVANELlA, L. et al. Politicas e sistema de saúde no Brasil. 2. Ed. rev. e ampl. Rio de Janeiro: Editora Fiocruz, 2012.

GIOVANNI, Geraldo di. Sistema de proteção social: uma introdução conceitual. In: OLIVEIRA, Marco Antônio (Org.). Reforma do Estado e políticas de emprego no Brasil. Campinas, São Paulo: Unicamp, IE, 1998.

MARSHALL, Thomas Humphrey. Cidadania, classe social e status. Rio de Janeiro: Zahar, 1967.

ORGANIZAÇÃO MUNDIAL DA SAÚDE (OMS). Constituição da Organização Mundial da Saúde. São Paulo: Unesp, 1946. Disponível em: <http://www.direitoshumanos.usp.br/ index.php/OMS-Organização-Mundial-da-Saúde/constituicao-da-organizacao-mundial-dasaude-omswho.html>. Acesso em: 31 jan. 2015.

PEREIRA, Potyara Amazoneida Pereira. Política social: temas \&questões. São Paulo: Cortez, 2008.

POLANYI, Karl. A grande transformação: as origens de nossa época. 3. ed. Rio de Janeiro: Campus, 1980.

POLIGNANO, Marcos Vinícius. História das politicas de saúde no Brasil: uma pequena revisão. Cuiabá: Secretaria de Estado de Saúde de Mato Grosso, 2001. Disponível em: <http://www.saude.mt.gov.br/upload/documento/16/historia-das-politicas-de-saude-no-brasil-\%5B16-030112-SES-MT\%5D.pdf>. Acesso em: 10 out. 2017.

RAMOS, Edith Maria Barbosa Ramos. Universalidade do direito à saúde. São Luís: Edufma, 2014. 
RAMOS, Edith Maria Barbosa; MADUREIRA, Amanda Silva; SENA, Jaqueline Prazeres de. $\mathrm{O}$ processo de redemocratização e o novo padrão de proteção do direito à saúde no Brasil. Cadernos Ibero-Americanos de Direito Sanitário, Brasília, v. 2, n. 2, p. 51-67, jul./dez., 2013. Disponível em: <http://publicaciones.fmdv.org/ojs/index.php/cuadernosderechosanitario/ article/view/8>. Acesso em: 10 out. 2017

RAMOS, Edith Maria Barbosa Ramos; MIRANDA NETTO, Edson Barbosa de. Histórico do sistema normativo de saúde no Brasil: uma análise da construção do ordenamento jurídico da saúde pós-1988. Revista Debates, Porto Alegre, v. 11, n. 1, p. 43-66, jan./abr. 2017. Disponível em: < file://C:/Users/Edith\%20Ramos/Downloads/71740-301110-1-PB\%20 (1).pdf>. Acesso em: 10 out. 2017

SANTOS, Lenir. Direito à saúde e Sistema Único de Saúde: conceito e atribuições. O que são açôes e serviços de saúde. In: SANTOS, L (Org.). Direito da Saúde no Brasil. Campinas: Saberes, 2010. p. 145-179.

SERRANO, Mônica de Almeida Magalhães. O Sistema Único de Saúde e suas diretrizes constitucionais. São Paulo: Verbatim, 2009.

SOUZA, Jorge Munhós de. Diálogo institucional e direito à saúde. Salvador: JusPODIVM, 2013.

WEICHERT, Marlon Alberto. Saúde e federação na Constituição brasileira. Rio de Janeiro: Lumen Juris, 2004. 